\title{
Os conflitos em torno do turismo comunitário na Prainha do Canto Verde (CE)
}

\author{
The conflicts regarding community-based tourism in \\ Prainha do Canto Verde (CE, Brazil)
}

\section{Rafael Ângelo Fortunato, Lucas Siqueira Silva}

\begin{abstract}
RESUMO
O presente artigo tem como objetivo mostrar como o turismo comunitário na Prainha do Canto Verde (CE) produz conflitos internos gerados pela atividade. Entrevistaramse os atores sociais envolvidos na atividade utilizando-se a seguinte questão norteadora: como é o turismo na Prainha? Ao analisar as respostas obtidas, observa-se que a visão sobre qual tipo de turismo deve ser realizado, não é algo homogêneo, ocorrendo divergências entre seus membros. Situação que se torna mais evidente com a criação de uma nova associação de moradores contrária à manutenção do modelo comunitário, com a justificativa de possibilitar maior inserção dos habitantes, tendo como exemplo o destino de Canoa Quebrada. Conclui-se que o caso é um exemplo para pensar a complexidade que o turismo comunitário está inserido e os campos de disputas que perpassam sua configuração.
\end{abstract}

PALAVRAS-CHAVE: Turismo Comunitário; Conflitos; Organização Social.

\begin{abstract}
This papers aims to demonstrate how community-based tourism in Prainha do Canto Verde, in the state of Ceará produces internal conflicts generated by the activity. The social actors involved in the activity were interviewed using the following question: How is the tourism ina Prainha? By analyzing the responses, it is observed that the view on which type of tourism should be done, is not homogeneous, occurring differences among its members. This situation becomes more evident with the creation of a new residents' association, contrary to maintaining the base-community model, with the justification to allow greater integration of people, taking as example the destination of Canoa Quebrada. It is concluded that the case is an example to think about the complexity that community based tourism is inserted and the fields of disputes that go through your configuration.
\end{abstract}

KEYWORDS: Community Tourism; Conflicts; Social Organization. 


\section{Introdução}

As discussões em torno do turismo comunitário ganham evidência em âmbito nacional e internacional, pois se acredita que este pode ser um importante instrumento de inclusão das populações receptoras. Tais iniciativas surgiram como resposta à lógica de massificação e "elitização" do turismo em nível mundial e também como uma forma das comunidades enfrentarem os problemas socioambientais ocorridos em função desse modelo.

O turismo desenvolvido na Prainha do Canto Verde - CE tornou-se um caso "bem sucedido" para o que se convencionou chamar de turismo comunitário. Na dissertação de mestrado elaborada por Mendonça (2004), a Prainha é apresentada como "a Canoa que não quebrou e a fonte que não secou".

Esta referência sinaliza para perspectivas de sustentabilidade no turismo, em comparação as localidades do estado do Ceará que se desenvolveram turisticamente, mas não foram capazes de evitar problemas socioambientais, a saber, Canoa Quebrada e a Praia do Fontes.

Neste artigo, apresenta-se uma Prainha prestes a "quebrar", pelo menos no que tange a sólida e pioneira Associação de Moradores. Pretende-se mostrar como os sujeitos, que criaram uma nova associação enquadram seus discursos em relação ao turismo desenvolvido na Prainha, visto que, se apresentam de alguma forma, em oposição ao trabalho que vinha sendo realizado. Apresenta-se, dessa forma, certa ambivalência no campo do turismo comunitário.

Acredita-se que esta investigação é importante para relativizar posições que procuram marcar o turismo comunitário como um ideal de turismo a ser atingido e muitas vezes apresentado de uma maneira "romantizada" e sem conflitos. Parte-se do pressuposto de que a dialética e os conflitos são parte dos processos que envolvem indivíduos e suas organizações, pois existe sempre uma fronteira bem tênue entre os interesses particulares e coletivos.

Para coleta de dados trabalhou-se com a observação participante, em alguns casos, optou-se por conversas e participação em reuniões. Trabalhou-se também com entrevistas semiestruturadas, tendo como base a seguinte questão norteadora: como é o turismo na Prainha?

$\mathrm{Na}$ segunda parte do artigo se discute o turismo comunitário na Prainha do Canto Verde. Na terceira parte, apresentam-se os conflitos em torno do turismo na Prainha e os modos como o mesmo vem sendo apropriado por um determinado grupo que percebe no turismo uma oportunidade para melhoria da qualidade de vida, mas tem dificuldades de se inserir na atividade, e por fim, apresentam-se as considerações finais.

\section{Aspectos conceituais do turismo comunitário}

A Organização Mundial do Turismo (OMT), em seu Código Mundial de Ética para o Turismo, afirma em seu Art. 5ำ, item 1: "As populações e comunidades locais 
se associarão às atividades turísticas e terão uma participação equitativa nos benefícios econômicos, sociais e culturais que referem, especialmente na criação direta e indireta de emprego que ocasionem" (OMT, 1999, p.6).

Uma alternativa capaz de proporcionar a possibilidade de inclusão das populações receptoras é o chamado turismo comunitário, surgido como resposta à lógica de massificação e elitização turismo em nível mundial.

De acordo com o exposto por Maldonado (2009), o turismo comunitário é resultado direto da necessidade de diversificação dos destinos turísticos em face a exigência de uma demanda a procura por novas modalidades de turismo, dentre as quais se destacam o turismo cultural e o turismo de natureza, que ganhou força a partir da década de 1980.

Para atender essa nova demanda, o mercado turístico internacional pressionou diversas comunidades residentes em locais com rico patrimônio natural e que possuem manifestações culturais únicas, no sentido de transformá-las em produtos viáveis. ONGs e instituições internacionais atuaram no sentido de convencer um grande número de comunidades a receberem turistas em seus territórios, pois se tratava de uma nova alternativa de geração de renda e capaz de conservar os recursos naturais e a biodiversidade local.

Irving (2009) afirma que, em âmbito global, a novas preferências e exigências da demanda turística, cada vez mais incorporam temas como a responsabilidade social e ambiental, e provocam uma "resignificação" da atividade turística, resultando em uma nova postura por parte das operadoras e agências turísticas.

Estas por sua vez, voltam sua atenção para localidades até então esquecidas no mercado global, mas que possuem imenso potencial de proporcionar experiências diferenciadas para os turistas através de vivências mais autênticas e novas aprendizagens, características que os principais destinos consolidados internacionalmente já não são capazes de promover.

No entendimento de Zaoual (2009), a necessidade de ter contato direto com a diversidade, em um mundo onde é cada vez mais difícil encontrar referências, pertencimento e intercâmbios culturais, exigem a procura de sentido por parte dos atores envolvidos. Em relação ao turismo, isso não é diferente, pois aqueles que se deslocam atualmente abandonam a passividade e desejam atuar responsável e solidariamente, quando estão em contato com mundos diferentes dos seus.

A mesma tendência se verifica quando a análise é realizada com os atores locais. Pois a partir da mudança do paradigma turístico, tem como objetivo maior participação nos processos de desenvolvimento turístico, no sentido de evitar os efeitos já experimentados e sofridos no modelo anterior de turismo massificado, dentre os principais a marginalização econômica e social, perda da identidade cultural, esgotamento dos ecossistemas.

Para Coriolano (2006), ao contrário do modelo hegemônico e centralizador dos grandes empreendimentos internacionais, em que o lucro é o principal objetivo a ser 
alcançado e a qualquer custo, o novo modelo tem como característica a priorização dos interesses das comunidades locais, a valorização de sua identidade e a conservação do ambiente em que vivem.

Tal como salienta Irving (2009), a constatação de que o turismo planejado e realizado nos moldes anteriores não foi capaz de evitar a inclusão marginal das populações locais, opera uma mudança em relação aos planos elaborados. Pois a irreversibilidade do fenômeno turístico e do processo de globalizante implica na necessidade de que o planejamento de tais iniciativas considerem aspectos como a valorização do local e de suas identidades culturais, contudo para que isso ocorra é necessário conceber e desenvolver alternativas criativas e que superem os métodos tradicionais.

Outro aspecto importante do turismo comunitário é a sua capacidade de integração com as atividades econômicas preexistentes nas comunidades. Como exposto anteriormente, no turismo globalizado as comunidades são convencidas a abandonar suas atividades tradicionais para trabalharem em subempregos, porém no turismo comunitário atividades como a agricultura, pesca e artesanato são fortalecidas e valorizadas, o que resulta na geração de trabalho para a população local, inserção dos pequenos empreendimentos da comunidade e inclusão de mulheres e jovens nas (CORIOLANO, 2009).

A partir do envolvimento comunitário segmentos como o ecoturismo e o turismo rural $^{1}$ possuem grande potencial de nutrir uma lógica diferente da capitalista, devido as suas características intrínsecas de respeito às populações receptoras, sua cultura e o ambiente em que vivem.

De acordo com o cenário exposto, as discussões sobre o turismo passam a incluir aspectos como a conservação do patrimônio natural e cultural, geração de benefícios para as comunidades, inclusão de seus membros durante todas as etapas da atividade e autonomia no processo decisório (IRVING, 2002).

As atividades turísticas realizadas em áreas que possuem patrimônios naturais e culturais significativos, porém com um nível de fragilidade bastante elevado, devem ser rigorosamente monitoradas, no sentido de maximizar as oportunidades de visitação e recreação, e minimizar os impactos negativos, considerando todas as dimensões de sustentabilidade das localidades definidas como destinos turísticos, pois a grande maioria dos locais não está preparada para receber um grande fluxo turístico.

É importante ressaltar que turismo comunitário surge como um método de desenvolvimento baseado numa aproximação participativa, que possui metodologias diversas e que tem em comum sua ligação com a conservação ambiental e desenvolvimento socioeconômico, pois tais inciativas ocorrem principalmente no entorno e dentro de áreas protegidas, tendo como premissa a participação das comunidades e a geração de benefícios para as mesmas. (GOODWIN; SANTILLI, 2009).

Ao garantir a oportunidade dos atores locais atuarem como protagonistas da atividade durante as etapas de planejamento, organização, gestão e operação, o turismo de base comunitária é capaz proporcionar um compartilhamento equânime dos benefícios gerados pelo aproveitamento das diversas atividades produtivas existentes 
em determinada localidade. Pois, surge como uma solução viável e de estímulo do desenvolvimento local e a inclusão das comunidades através da participação democrática.

A implantação adequada do turismo comunitário deve pressupor o envolvimento da comunidade receptora em seu planejamento durante todas as etapas. Oferecendo-lhes a possibilidade de decisão no que tange ao nível de desenvolvimento que desejam. É imprescindível que o trade turístico, poder público e organizações do terceiro setor, os auxiliem a atingir os objetivos propostos.

Nesse sentido, para que sejam alcançados é fundamental que tais iniciativas tenham como premissa básica a participação local. Faz-se necessário envolver a comunidade, não somente em relação aos possíveis empregos, mas também no processo de planejamento e de tomada de decisão, algo que deve ser sempre estimulado pelos gestores através de workshops, oficinas e cursos de capacitação.

O que resulta na maximização das habilidades e saberes que existem dentro da própria comunidade, o que além de proporcionar maior autenticidade ao produto turístico, garante um alto nível de satisfação em relação à experiência realizada pelo visitante.

Diversos autores salientam que a participação comunitária é um elemento chave para o sucesso de empreendimentos com as características citadas. Sendo o grau de comprometimento fator determinante para a sua continuidade.

Contudo, para que esse modelo de atividade se realize de maneira plena é necessário que as instituições governamentais, cooperação pública e a sociedade civil organizada auxiliem os empreendimentos comunitários a superar suas limitações de ordem histórica, que os impossibilitam de alcançar seu pleno potencial como indivíduos e como comunidade, para atingir o bem-estar que tanto almejam.

A formação de diversos tipos de parcerias entre as organizações direta e indiretamente envolvidas na realização da atividade sejam particulares, governamentais e aquelas que representam a sociedade civil. É de vital importância que todos os atores sociais estejam envolvidos no processo.

Não se trata de reduzir o debate entre dois modelos localizados em polos opostos, visto que os modelos de desenvolvimento turístico apresentam enorme variedade. Contudo, o fortalecimento de atividades comunitárias é capaz de valorizar aspectos singulares e promover um número iniciativas comunitárias locais, que devido às práticas hegemônicas não ocorrem.

A reutilização de metodologias de comunitário bem sucedidas é recomendável, porém aplicá-las sem as adaptações necessárias em relação às especificidades de cada localidade, é algo contraditório, pois esse novo paradigma surge em contraposição a reprodução em série dos antigos modelos elaborados que não consideravam as características intrínsecas das localidades.

Um de seus aspectos fundamentais é sua elevada capacidade de proporcionar as comunidades receptoras a ampliação de sua participação democrática e melhoria 
da qualidade de vida, independente do tipo de organização que as comunidades escolham. A realização de parcerias é condição essencial para democracia participativa e a sustentabilidade.

Tal como salienta Brohman (1996, p.60) ${ }^{2}$ :

\begin{abstract}
O desenvolvimento do turismo de base comunitária deve buscar o fortalecimento das instituições destinadas a melhorar a participação local e promover o bem estar econômico, social e cultural da maioria popular. Também deve buscar uma aproximação harmônica e balanceada para o desenvolvimento que enfatize considerações como a compatibilidade de várias formas de desenvolvimento com outros componentes da economia local, a qualidade do desenvolvimento tanto cultural como ambiental, e as necessidades divergentes, interesses e potencialidade da comunidade e de seus habitantes.
\end{abstract}

A análise da produção acadêmica, internacional e nacional sobre o turismo de base comunitária aponta para uma grande diversidade no que tange aos elementos chave do tema. Em função da diversidade de casos e experiências, que possuem características diferenciadas, não existe um conceito único e fechado de turismo de base comunitária, pois esse apresentando de diferentes maneiras, devido a cada realidade analisada.

Goodwin e Santilli (2009) salientam que, apesar de ser difundido a mais de 30 anos como um tipo de desenvolvimento em que as necessidades sociais, ambientais e econômicas das comunidades locais são satisfeitas através da oferta de um produto turístico, muitos dos projetos que foram implantados em países em desenvolvimento não foram devidamente monitorados, tanto em relação ao seu êxito quanto ao seu fracasso, o que impossibilitou a quantificação dos benefícios reais para as comunidades.

Esse cenário ocorre em função do apelo que o turismo de base comunitária e o ecoturismo possuem, principalmente em relação ao turismo de massa, o que impede sua submissão a análises críticas e na ausência de estudos sobre a geração de benefícios para as comunidades.

Apesar de uma demonstração mínima dos benefícios ter sido realizada, as ideias permanecem atrativas principalmente porque muito pouco é feito para mensurar a real capacidade dessas modalidades de turismo para proporcionar a conservação dos territórios e os benefícios para as comunidades locais.

$\mathrm{Na}$ mesma pesquisa os autores indicam que existe uma disparidade entre as visões dos especialistas em denominar projetos bem-sucedidos e aqueles que gerenciam os que são identificados como bem sucedidos. Ainda existe pouco consenso entre os especialistas sobre o significado do conceito e devido ao fato de que estes são utilizados de maneira bastante flexível, e seu rigor é insuficiente. Portanto recomendam que os conceitos não sejam utilizados indefinidamente. 


\section{Sobre o turismo comunitário na Prainha do Canto Verde (CE)}

Durante a década de 1990, o litoral nordestino e o principalmente o do estado do Ceará passou por grandes transformações espaciais. Esse processo teve sua intensificação após a publicação do Programa de Desenvolvimento do Turismo no Nordeste - PRODETUR-NE e as ações dos governos estaduais, que tinham uma política agressiva de captação de grandes complexos hoteleiros internacionais.

O resultado foi uma intensiva ocupação de todo o litoral da região, gerando uma nova divisão territorial entre os empreendimentos e as comunidades locais. $\mathrm{Na}$ maioria dos casos a relação entre os complexos hoteleiros e as comunidades era praticamente inexistente. Em função do modelo internacional a prioridade era em relação aquilo que os turistas desejam em detrimento aos habitantes das áreas do entorno desses espaços.

O caso cearense apresentou em sua maioria, situações arbitrárias em que os interesses externos ditaram as ações. Coriolano (2009) cita que em Jericoacoara e Canoa Quebrada, a presença excessiva de investidores estrangeiros sufocou o mercado local. Além disso, ambas as comunidades foram expropriadas de suas terras e sendo estas profundamente alteradas em função dos complexos turísticos que foram construídos.

A recente valorização do litoral nordestino para fins turísticos e de lazer resultou em grande especulação imobiliária. Esse processo teve como consequência à "expulsão" das comunidades oriundas desses territórios em função da necessidade de reorganização do espaço para que a infraestrutura turística fosse capaz de se apropriar dos locais (CORIOLANO, 2009).

A instalação de grandes empreendimentos turísticos que não tinham comprometimento com o desenvolvimento local ${ }^{3}$ provocou um processo que intensificou a centralização do poder, dependência econômica e agressões à base de recursos naturais. A mesma autora afirma que:

A necessidade de as comunidades passarem a interferir em seu próprio crescimento, em busca de maior dinamismo nas atividades econômicas locais, e a lutar por uma melhor distribuição de riqueza e renda impuseram-se, sobretudo, desde que os efeitos da globalização se fizeram sentir. (CORIOLANO, 1998, p.135).

Cada vez mais surgem movimentos de resistência nas comunidades, com o objetivo de valorizar a diversidade existente e proteger as características únicas encontradas nos mais variados territórios. Nesse contexto, o turismo comunitário propõe uma mudança de paradigma, em que o turismo passa a ter como objetivo, maior participação das populações nos planos de desenvolvimento turístico.

Portanto, o turismo comunitário é um contraponto ao turismo de resorts e de megaempreendimentos implantado no estado do Ceará, sendo uma alternativa de de- 
senvolvimento local por meio da participação comunitária, pois o controle das atividades fica a cargo da população receptora, e é nesse contexto que a proposta da Prainha do Canto Verde - CE se insere.

A Prainha localiza-se no litoral cearense, distante $126 \mathrm{~km}$ de Fortaleza, no município de Beberibe e é integrante da Rede Cearense de Turismo Comunitário - TUCUM, que envolve além da Prainha, mais 11 comunidades do litoral do Estado em suas atividades. A Rede TUCUM consiste em "uma articulação de comunidades que se propõe a realizar o turismo comunitário no Ceará, integrado a perspectiva de fortalecer a relação entre sociedade, cultura e natureza, com justiça ambiental' (TUCUM, 2010, p.8).

A função da rede TUCUM, segundo seu fundador, é reunir as experiências de diversas localidades para capacitar pessoas e fazer a promoção do turismo, pois segundo ele "o mesmo esforço para promover um atrativo promove dez". E na visão da rede o turismo comunitário é "aquele no qual as populações locais possuem o controle efetivo sobre o seu desenvolvimento e gestão, e está baseado na gestão comunitária e familiar das infraestruturas e serviços turísticos, no respeito ao meio ambiente, na valorização cultural local e na economia solidária".

De acordo com o exposto por Mendonça (2009, p. 289), "o turismo na Prainha do Canto Verde representa um modelo inovador, tendo como premissa a construção de um projeto de base comunitária, no qual os moradores têm participação efetiva em sua concepção, desenvolvimento, implantação e gestão".

O turismo comunitário na Prainha do Canto Verde é considerado uma das experiências pioneiras e mais bem sucedidas dessa modalidade no país, tendo recebido o prêmio TODO! $99^{4}$ para o Turismo Socialmente Responsável da ONG alemã The Studienkreis für Tourismus und Entwicklung.

Para conter o avanço da especulação imobiliária na localidade, foi criada através do decreto $\mathrm{s} / \mathrm{n}^{\circ}$ de 05 de junho de 2009 a Reserva Extrativista (RESEX) ${ }^{5}$ da Prainha do Canto Verde consolidando o direito à posse e a propriedade aos moradores da Prainha do Canto Verde. A criação da RESEX em âmbito federal vai de encontro com a necessidade de luta pela garantia de posse de terra das comunidades frente ao processo de especulação imobiliária ocorrido em todo litoral cearense.

Para o coordenador de turismo da Prainha, o turismo no local começou a se organizar por meio de conselhos de pesca, de saúde, de educação, do turismo e da terra. Nas palavras do coordenador, "a gente foi arrumando a casa por prioridades". local:

A seguir, o coordenador de turismo da Prainha explica o início do turismo no

A ideia do turismo foi consolidada em 1994 para saber que tipo de turismo a gente queria para a comunidade, na época me lembro que a gente começou a chamar as pessoas para discutir o turismo, desse encontro saímos com uma proposta de levar a ideia do turismo comunitário a um seminário, chamar ONGs, representantes da prefeitura, criamos o primeiro seminário de ecoturismo de base comunitária de lá 
saíram várias propostas, decidimos trabalhar como o turismo de base comunitária para gerar renda para comunidade complementando a pesca... O turismo já é considerado hoje como aumento na qualidade de vida.

Outro ator envolvido na questão do turismo ressaltou que a comunidade local realizou pesquisas de campo em localidades vizinhas que já trabalhavam com o turismo há mais tempo. O resultado desse diagnóstico apontava para o trabalho com o turismo comunitário. Seria um turismo desenvolvido pela própria comunidade e em 1998 foi lançado o atual projeto de turismo comunitário.

Segundo os atores locais, a decisão de trabalhar com o turismo partiu da própria comunidade e logo se fizeram o seguinte questionamento: que tipo de turismo queremos? "A resposta a esta questão foi o turismo do tipo comunitário" explica o morador.

Tal como enfatiza Ribeiro (2009, p.108) o turismo comunitário consiste em uma:

Forma de organização empresarial sustentada na propriedade e na autogestão dos recursos patrimoniais comunitários, como o arranjo das práticas democráticas e solidárias no trabalho e na distribuição dos benefícios gerados pela prestação de serviços turísticos, com vista a fomentar encontros interculturais de qualidade com os visitantes.

No local existem pousadas domiciliares geridas por famílias da comunidade e de acordo com morador local "as pessoas se juntam no conselho de turismo para trabalhar junto com uma economia mista, parcialmente é propriedade individual, mas parcialmente é uma gestão comunitária".

Rodrigues (2007) salienta que apesar de modestos, as principais características desses empreendimentos, são a criatividade e inovação. Tais iniciativas são elaboradas através de sinergias estabelecidas nos próprios locais, o que permite o envolvimento da população e resultando na geração e distribuição igualitária dos benefícios oriundos da atividade.

Para alguns moradores que trabalham com o turismo a atividade é considerada de alta qualidade, pois é possível ouvir que "nós não temos turista sexual", ou seja, um cenário bastante comum no estado do Ceará, especialmente na capital Fortaleza.

Existem muitos turistas que buscam a Prainha para questões relacionadas a estudos, em visita ao local, havia um grupo de pesquisadores espanhóis interessados no modo de organização social da Prainha e outros representando uma instituição de ensino colhiam dados para registrar o aumento dos ganhos econômicos em um determinado período de tempo. Já outros, buscam o convívio com a comunidade e "o clima de paz". 
Ao serem questionados sobre como se sentiam com a presença do turista, o morador responde que é muito bom saber que as pessoas procuraram a Prainha e procura justificar dizendo "a gente começa a perceber que as pessoas estão fugindo daquele caos de cidade grande, praias badaladas".

Devido a esse novo enfoque, visitantes e turistas são capazes de interagir de uma forma mais dinâmica, uma vez que as tradições, impressões, necessidades e desejos de ambos são compartilhados.

O coordenador de turismo ao ser questionado sobre o perfil do turista que frequenta o local disse as seguintes palavras: "é muito de convívio, elas querem saber muito como é a comunidade, como é a pesca, como as pessoas desenvolvem este turismo dentro da comunidade, como é um dia de pesca no mar, o que os pescadores pescam".

A principal motivação do turista que visita a Prainha está ligada a tranquilidade do local, as belezas naturais e as histórias de lutas dos moradores, na maioria das vezes este turista promete voltar visto a relação de proximidade estabelecida com a população local, para uma dessas turistas "é uma experiência realmente humana". Outra disse: "eu quero que a civilização jamais chegue aqui. Eu sou cearense e já vi praias que perderam sua beleza".

Dentre todas estas questões o turismo na Prainha mostra-se capaz de envolver aspectos emocionais, pois segundo uma moradora que recepciona os turistas, "teve um rapaz que me abraçou e disse coisas tão lindas para mim que eu cresci naquele momento, eu me fortalecia, aquele cansaço que eu estava aquilo acabou ai eu disse para ele meu filho eu estava precisando ouvir isso de você". Percebe-se nesses casos a multidimensionalidade do turismo realizado em proximidade com um modo de vida local e organizado por ele.

Para o coordenador do turismo,

\begin{abstract}
Interagir com o turista, foi um obstáculo que apareceu... Os turistas vão vir a aqui e agente vai ter que ficar perguntando o que eles querem o que não querem isso foi um obstáculo por que todo mundo já estava acostumado com a pesca mesmo, mas isso está mudando (ressignificação da identidade) procuram curso de capacitação, recepção, atendimento, hoje todos os jovens da comunidade são abertos perguntam, falam, sai para fazer uma trilha, topando seu próprio desafio de conhecer outras culturas.
\end{abstract}

Em muitos casos os turistas voltam para ficar no mesmo lugar e enviam cartões postais e presentes para as pessoas da comunidade. O fundador da rede se refere a uma relação não só de turista com os donos de pousada, mas uma relação humana acima de tudo.

A busca de vínculos entre os hóspedes e os anfitriões, surge como uma das 
principais características diferenciais do turismo comunitário, se configurando como relações que ultrapassam a dimensão econômica existente nas relações de hospitalidade das práticas comuns da atividade turística (BURTZYN; SANSOLO, 2009).

Todos os atores entrevistados foram unânimes em suas respostas sobre a principal característica do turismo por ora apresentado "é um turismo organizado pelas pessoas do local' e no caso da Prainha, a criação da Reserva Extrativista restringe a especulação imobiliária e cria um cenário propicio para o desenvolvimento do turismo de base comunitária.

Porém, atualmente existem conflitos em torno do turismo realizado no local, visto que uma parcela da população não conseguiu obter benefícios por meio do turismo e sente-se "injustiçada" com a concentração da atividade "nas mãos" de algumas famílias.

\title{
Os conflitos em torno do turismo comunitário na Prainha do Canto Verde
}

Alguns moradores que tem em sua principal atividade a pesca começaram a perceber que uma parte das pessoas do local estava conseguindo maiores benefícios através da atividade turística, e deste modo, pensavam em se inserir na atividade e auferir maiores ganhos, mas sem sucesso.

Segundo envolvido com o turismo na localidade, "hoje a gente tem 45 pessoas que vivem diretamente do turismo, mais indiretamente o turismo abrange mais de 100 pessoas". O coordenador de turismo mostra-se disposto a tentar envolver um maior número de pessoas na atividade. A seguir ele explica como funciona o processo de inserção da comunidade em relação ao turismo na localidade:

\begin{abstract}
A gente tem uma preocupação, desde quando montamos uma cooperativa informal como é que a gente ia abranger todas as pessoas das comunidades com relação a fatia da economia do turismo, assim, a gente está sempre destinando as sobras da cooperativa...criamos um fundo social para investimento na comunidade. $20 \%$ da renda é destinada a educação, a pesca, as festas, o que gera de recursos com o turismo beneficia de uma certa forma a todas as pessoas da comunidade. Ficamos nove anos como cooperativa informal de turismo, mas agora voltamos a ser conselho a gente começou a perceber que a cooperativa estava afastando as pessoas por que ela é formada... No conselho cada um paga uma taxa por empreendimento ou por serviços prestados cada equipamento tem um certo valor eles funcionam como se fosse uma cooperativa, eles pagam cotas. O conselho faz a promoção da atividade
\end{abstract}

No entanto, para uma parcela da população a pesca é ainda a atividade principal da Prainha, sendo o turismo, para alguns deles seu complemento e, apesar dos contratempos, é neste sentido que o turismo ocorre na localidade, apesar de alguns 
pescadores ainda residirem em casa de palha de coqueiro e sonhar com uma casa de tijolos.

A RESEX tão almejada pela maior parte da população, agora apresenta uma força ambivalente, pois por um lado protege o ambiente natural e regulariza os imóveis dos moradores, e por outro lado, provoca uma retração no fluxo de turistas que dificulta a inserção de outros atores sociais, já impregnados pela ideia do "dinheiro fácil", que pelo menos segundo os pescadores "mais fácil e garantindo que no mar".

Devido a tal impasse criou-se uma segunda associação de moradores que defende interesses opostos em relação à criação da RESEX e que tem financiamento de agentes externos com interesse na "belíssima" praia da localidade. Percebe-se, que a tentativa de seguir o padrão de desenvolvimento turístico da Praia das Fontes e de Canos Quebrada persiste, pois segundo alguns moradores a localidade precisa de investimentos.

Desse modo, percebe-se que o modelo de desenvolvimento turístico arbitrário e centralizador apresentado por Coriolano (2009) ainda encontra força no imaginário de alguns atores sociais da Prainha, tendo em vista que vários empresários da região influenciam e investem dinheiro na nova associação.

No caminho para amenizar estas questões o coordenador do conselho de turismo da Prainha disse que estão trabalhando com um fundo para poder beneficiar a comunidade não inserida na atividade turística e segundo um dos expoentes do turismo na comunidade a atividade ainda não atingiu todo seu potencial.

Os atores sociais na Prainha faziam referência à vizinha "Canoa Quebrada" como um local que não gostariam de ser, mas por outro lado, ouve-se dos partidários da nova Associação de moradores, que deveria ser igual à Canoa argumentando que "pelo menos lá tem emprego e aqui?".

Diante deste cenário, visitou-se Canoa Quebrada, e em conversas com os pescadores percebeu-se que eles preferiam trabalhar com o turismo referindo-se "a pesca do turista" como sendo mais fácil e garantida em relação às incertezas da pesca artesanal, mas relatam que na baixa temporada, ou quando não tem turista, ainda vão para o mar, aonde chegam a ficar cinco noites dormindo nas pequenas jangadas.

Nesta experiência ficaram nítidas as diferenças do turismo comunitário da Prainha e do turismo realizado em Canoa Quebrada, denotando novamente as ambivalências presentes, pois o pescador estava "feliz" trabalhando com o passeio de jangada, no entanto, era "explorado" pelo restante da cadeia do turismo (operadores, hotéis e agências de viagem) que organizavam o passeio e repassavam uma pequena quantia ao pescador, agora condutor de passeios na jangada.

Na prainha do Canto Verde isso se dá de outra forma, sendo todo o montante do dinheiro passado para as mãos dos pescadores, no entanto, com um fluxo reduzido de turistas, ainda anseiam por melhores condições de vida.

A fala de uma moradora local que trabalha com o turismo define bem esta situação: "turismo comunitário para mim é essa distribuição na comunidade que ajuda 
não todo mundo, porque nem todo mundo é envolvido no turismo, mas a maioria das pessoas". Para reforçar essa ideia, outro morador disse:

\begin{abstract}
Quem não teve a ideia de construir algo que pudesse se beneficiar através do turismo, hoje se sente fora como se não fizesse parte deste mundo e nosso intuito não é este, nosso intuito é trazer para que ele possa assumir alguma parte, para que ele possa ser beneficiado com seu próprio trabalho... Eu sinto que fica constrangedor por que quem ganha dinheiro é fulano, porque tem uma pousada (é o caso dele), uma mercearia e nós, principalmente pescadores, o mar não está bom para peixe e então depende de outra atividade... Nos momentos que eles não estão no mar que possam ter outros benefícios através do turismo para essas famílias.
\end{abstract}

Portanto, ao analisar a atual situação da Prainha do Canto Verde, em que grupos de posições antagônicas disputam a preferência por um determinado modelo de turismo, seria um equívoco afirmar que o turismo comunitário não acarreta tensões e conflitos internos e continuar difundindo uma ideologia "romantizada" do ideal comunitário.

Torna-se relevante pensar nos conflitos e nas ambivalências para que ocorram avanços conceituais, sem desconsiderar seu aspecto fundamental que proporciona as comunidades receptoras a ampliação de sua participação democrática e melhoria da qualidade de vida por meio do desenvolvimento local.

\title{
Considerações finais
}

Ao garantir a oportunidade dos atores locais atuarem como protagonistas da atividade durante as etapas de planejamento, organização, gestão e operação, o turismo comunitário é capaz de proporcionar um compartilhamento equânime dos benefícios gerados pelo aproveitamento das diversas práticas produtivas existentes em determinada localidade, e estimular o desenvolvimento local e a inclusão das comunidades através da participação democrática.

Diversos autores salientam que a participação e envolvimento da população receptora é um elemento chave para o sucesso de empreendimentos no campo do turismo comunitário, sendo o grau de comprometimento fator determinante para a sua continuidade.

No entanto, mesmo com todas essas potencialidades, que sinalizam para a sustentabilidade da atividade, observa-se que posições simplistas podem "pintar" um tipo de "turismo ideal" sem considerar uma série de conflitos tendo em vista as dificuldades de inclusão de uma parcela das pessoas das comunidades nas atividades produtivas. Nesse caso, em um contexto micro, mesmo o turismo comunitário pode reproduzir a lógica de "exclusão" no campo do turismo, contra a qual o movimento mar- 
ca seu contraponto e se fortalece.

Neste sentido, o artigo sinaliza para a importância de abordagens mais complexas e relativizadoras, que podem contribuir para o estudo do turismo comunitário, pois mesmo em localidades onde o modelo comunitário é apontado como um caso de sucesso, em algumas delas os interesses das comunidades em relação ao turismo estão longe de ser homogêneos.

\section{Referências bibliográficas}

BARTHOLO, R.; SANSOLO, D. G.; BURSZTYN, I. (Orgs.). Turismo de Base Comunitária: diversidade de olhares e experiências brasileiras. Rio de Janeiro: Letra e Imagem, 2009.

BRASIL. Lei no 9.985/00. Institui o Sistema Nacional de Unidades de Conservação da Natureza e dá outras providências. Brasília. 2000.

BROHMAN, J. New Directions in Tourism for the Third World. Annals of Tourism Research, 1996, 23(1):48-70.

BURSZTYN, I. BARTHOLO, R., DELAMARO, M. Turismo Para Quem? Sobre Caminhos de Desenvolvimento e Alternativas Para o Turismo no Brasil In: CORIOLANO, L.N.M.T. Do Local Ao Global: o turismo litorâneo cearense. Campinas. Papirus, 1998. 160.p

CORIOLANO, L.N.M.T. (org.). Arranjos Produtivos Locais do Turismo Comunitário: atores e cenários em mudança. Fortaleza. EdUECE, 2009.

GOODWIN, H.; SANTILLI, R. Community-Based Tourism: A Success? ICRT Occasional Paper No. 11. Leeds: ICRT \& GTZI, 2009.

IRVING, M.A. Reinventando a reflexão sobre turismo de base comunitária: inovar é possível? In: BARTHOLO, R.; SANSOLO, D. G.; BURSZTYN, I. (Orgs.). Turismo de Base Comunitária: diversidade de olhares e experiências brasileiras. Rio de Janeiro: Letra e Imagem, 2009.

MARTINS, J. S. A sociedade vista do abismo: novos estudos sobre exclusão, pobreza e classes sociais. 2ª ed., Petrópolis, Vozes, 2003.

MENDONÇA, T.C.M. Turismo e participação comunitária: "Prainha do Canto Verde, a 'canoa' que não quebrou e a 'fonte' que não secou?". Dissertação de mestrado. Rio de Janeiro: EICOS/UFRJ, 2004.

MENDONÇA, T.C.M.. Turismo Socialmente Responsável da Prainha do Canto Verde: Uma Solução em Defesa do Local Herdado. In: BARTHOLO, R.; SANSOLO, D. G.; BURSZTYN, I. (Orgs.). Turismo de Base Comunitária: diversidade de olhares e experiências brasileiras. Rio de Janeiro: Letra e Imagem, 2009. 
REDE BRASILEIRA DE TURISMO SOLIDÁRIO. Série Turisol de Metodologias: Turismo Comunitário - Turismo e Resistência na Zona Costeira Cearense - Rede Turisol, 2010. Disponível em: http://www.turisol.org.br/wp/wp-content/uploads/2011/02/ Livreto-Tucum.pdf. Acesso em: 29 maio de 2012

RIBEIRO, M. Turismo comunitário: relações entre anfitriões e convidados. In: PANOSSO NETTO, A.; ANSARAH, M. (Orgs.). Segmentação do mercado turístico: estudos, produtos e perspectivas. São Paulo: Manole, 2009.

RODRIGUES, A. B. Território, patrimônio e turismo com base local - uma relação inequívoca. In: SEABRA, G. (Org.). Turismo de Base Local: identidade cultural e desenvolvimento regional. João Pessoa: Editora Universitária - UFPB, 2007.

TENÓRIO, F. G. (Org.). Cidadania e Desenvolvimento Local. Rio de Janeiro: FGV; ljuí: Ed. ljuí, 2007.

ZAOUAL, H. Do Turismo de massa ao turismo situado - quais as transições? In: BARTHOLO, R.; SANSOLO, D. G.; BURSZTYN, I. (Orgs.). Turismo de Base Comunitária: diversidade de olhares e experiências brasileiras. Rio de Janeiro: Letra e Imagem, 2009.

\section{Notas:}

${ }^{1} O$ Ministério do Turismo conceitua o turismo rural como um "conjunto de atividades turísticas desenvolvidas no meio rural, comprometido com a produção agropecuária, agregando valor a produtos e serviços, resgatando e promovendo o patrimônio cultural e natural da comunidade". (MTUR, 2007, p. 7)

${ }^{2}$ Community-based tourism development would seek to strengthen institutions designed to enhance local participation and promote the economic, social and cultural well-being of the popular majority. It would also seek to strike a balanced and harmonious approach to development that would stress considerations such as the compatibility of various forms of development with other components of the local economy; the quality of development, both culturally and environmentally; and the divergent needs, interests and potentials of the community and its inhabitants.

${ }^{3}$ Para Tenório (2007) o desenvolvimento local procura reforçar a potencialidade do território mediante ações endógenas, articuladas pelos seus diferentes atores: sociedade civil, poder público e mercado.

${ }^{4}$ http://www.fortalnet.com.br/ fishnet/linktdetc.html

${ }^{5}$ O Sistema Nacional de Unidades de Conservação (SNUC) em seu Art. 20 define a Reserva de Desenvolvimento Sustentável como uma área natural que abriga populações tradicionais, cuja existência baseia-se em sistemas sustentáveis de exploração dos recursos naturais, desenvolvidos ao longo de gerações e adaptados às condições ecológicas locais e que desempenham um papel fundamental na proteção da natureza e na manutenção da diversidade biológica. 
Rafael Ângelo Fortunato: Universidade do Estado do Rio de Janeiro, Rio de Janeiro, RJ, Brasil.

Email: fortrafa@hotmail.com

Link para o currículo Lattes: http://lattes.cnpq.br/8616988019237581

Lucas Siqueira Silva: Universidade Federal Fluminense, Niterói, RJ, Brasil.

Email: lucas.siqueira@gmail.com

Link para o currículo Lattes: http://lattes.cnpq.br/6889374519983521

Data de submissão: 26 de junho de 2012

Data de recebimento de correções: 29 de novembro de 2012

Data do aceite: 29 de novembro de 2012

Avaliado anonimamente 